\title{
Avatares de la tradición oral en la era de la reproducción mecánica: la Morenica judeo-española hoy
}

\section{Transfigurations of oral traditions in the era of mechanical reproduction: The Judeo-Spanish Morenica today}

\section{Edwin Seroussi Bargman}

Universidad Hebrea de Jerusalén edwin.seroussi@mail.huji.ac.il ORCID iD: https://orcid.org/0000-0001-5006-1520

Susana Weich Shahak Universidad Hebrea de Jerusalén sweichshahak@gmail.com

\section{RESUMEN}

La canción sefardí Morenica ofrece un locus classicus para analizar los procesos de creación, transmisión y recepción que determinan el repertorio lírico judeoespañol diseminado en el presente a nivel global por artistas no-sefardíes via medios de comunicación de masas. Basado en evidencia literaria y musical en fuentes históricas y etnográficas, escritas y orales, este estudio ofrece un detallado análisis de como una versión determinada de Morenica adquirió un estatus casi canónico al ser reproducida en forma mecánica.

Palabras clave: cantar de boda, sefardí, Morenica, oralidad, medios de comunicación de masas. 


\section{EDWIN SEROUSSI BARGMAN Y SUSANA WEICH SHAHAK}

\section{Abstract}

The Sephardic song Morenica offers a locus classicus to analyze the processes of creation, transmission and reception that define the Judeo-Spanish song repertoire currently disseminated globally by non-Sephardic artists via mass media. Based on literary and musical evidence in historical and ethnographic sources, written and oral, this study offers a detailed analysis of how a given version of Morenica acquired quasi-canonical status when reproduced mechanically.

Key Words: wedding song, Sephardic, Morenica, orality, mass media.

Seroussi Bargman, E. \& Weich Shahak, S. (2022). Avatares de la tradición oral en la era de la reproducción mecánica: la Morenica judeo-española hoy. Cuadernos de Investigación Musical, (14), pp. 5-27.

Hacia el final del siglo XVIII, en Sarajevo o Venecia, documentaba el jazán (cantor de sinagoga) David Hacohen en su manuscrito aljamiado titulado Pizmonim veshirot vetishbahot ("Cantares y canciones y alabanzas"; National Library of Israel, Ms. Heb. $8^{\circ}$ 413, fol. 175b) los siguientes versos:

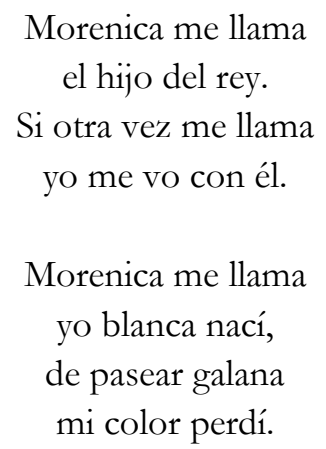

La canción que anotó el jazán Hacohen y que en este estudio la llamaremos "Morenica", continua con siete estrofas más, pero por el momento estas dos son suficientes para desarrollar un argumento que es principalmente musical y solo secundariamente literario (para texto completo véase la selección al final de este articulo). Durmiente en los archivos de bibliotecas, el manuscrito de Hacohen reaparece en público gracias a la iniciativa del gran estudioso de la canción sefardí, Moshe Attias, el cual publica la transcripción de esta canción en caracteres latinos en su magnífico volumen Cancionero sefardí (Attias, 1972, no. 12, pp. 6971). Profundo conocedor el acervo sefardí desde el seno de su propia familia salonicense e 
informado estudioso de las relaciones de este acervo con la lírica hispánica, Attias provee en su comentario a la canción que anotó Hacohen la siguiente nota que aquí traducimos parcialmente del hebreo: "Esta canción es una de las más difundidas en la diáspora sefardí, querida por todos, y no hay rincón en la cual no se la conoce. En la canción popular hispánica la figura de la agradable y dulce morenita es muy estimada... No nos alejaremos de la verdad si afirmamos que los orígenes de nuestra canción se encuentran en la lírica hispánica...". Attias limita sus observaciones al aspecto literario de la canción y no aventura ninguna hipótesis respecto a su melodía. El presente estudio pretende complementar el aspecto musical que Attias y otros investigadores que se ocuparon de están canción dejaron inconcluso ${ }^{1}$.

El destino de tradiciones musicales orales en la modernidad está determinado por una cadena de acciones discretas generadas por una red de agentes actuando en marcos y planos sociales diferentes, sean instituciones académicas, asociaciones culturales de subculturas étnicas, círculos artísticos, políticos o intereses comerciales. El cancionero sefardí ofrece una oportunidad de observar los resultados de fenómenos generados por redes de agentes dedicados de un lado a proteger la supervivencia en un repertorio considerado tradicional, y por lo tanto altamente valorado, cuando ya había perdido su funcionalidad en la vida comunitaria.

De otro lado, la canción sefardí permite observar los actores de las mismas redes sociales involucradas en su difusión, generalmente miembros de elites y activistas culturales dedicados a la conservación de tradiciones valoradas. Al poner estos materiales al acceso de nuevos públicos - recalcando una reminiscencia de lo que la tradición habría sido en generaciones anteriores, memorias envueltas en halos de nostalgia - se generan nuevos productos cuya naturaleza depende de los avatares e incluso de "accidentes" en los procesos de transmisión ${ }^{2}$.

\footnotetext{
1 El texto de la cantiga o cantica sefardí, que explica el color de la morena por causa de sus labores de trabajo, difiere del tema hebreo original del Cantar de los Cantares $(1,5)$ que dice "morena soy y garrida". Recientemente la reconocida historiadora Cruz Montero Garrido nos ha señalado que la diferencia entre el texto bíblico y la canción sefardí ("morenica soy y garrida" frente a "morenica soy pero garrida") "se remonta a la traducción al latín del texto bíblico por San Jerónimo en el siglo IV (Vulgata): Nigra sum sed formosa. que sustituyó la letra vav del hebreo ("y"), por la conjunción adversativa sed que en la Biblia Septuaginta había sido correctamente traducida al griego por xai ("y")". Es decir que la Vulgata introdujo una oposición donde no la había, considerando la morenez del cutis como un rasgo negativo de la que nació blanca de tez y explicando su causa (trabajo al aire libre). Con ello se desencadenó una serie de interpretaciones y exégesis que afectaron incluso a los comentarios de este verso de eruditos hebreos como el del célebre Rashi (Rabí Shelomo Yitzhaki, siglo XI) que dice: "Vosotros, amigos míos, (permitidme) que no sea baja (en consideración) ante vuestros ojos, a pesar de que mi marido me ha dejado por mi negrura, porque yo soy negra por causa del bronceado del sol, pero soy bella por la forma de (mis) bellos miembros, y si yo soy como las tiendas de Quedar, que se ennegrecieron por las lluvias, porque están siempre extendidas en los desiertos; es fácil para mi purificarme para ser como las cortinas de Salomón. Esto es una alegoría: la congregación de Israel dice a las naciones, 'yo soy negra por mis actos, pero yo soy bella por los actos de mis antepasados, e incluso entre mis actos hay algunos que son bellos'.” (Traducción de Taradach \& Ferrer, 2004, p. 402).

2 Estas premisas teóricas son similares a las presentadas por Seroussi, 2019.
} 


\section{EDWIN SEROUSSI BARGMAN y SUSANA WEICH SHAHAK}

La canción judeoespañola "Morenica" o con su nombre académico derivado del catálogo del Proyecto Folclor (colección de canciones en judeoespañol grabadas por la sección Ladino de la radioemisora Kol Israel) La llamada a la morena, ofrece un caso de estudio que ejemplifica tales procesos en forma clara. Sin duda es esta una de las canciones más difundidas del acervo lirico sefardí, sea el de tradición oral, escrita (ya desde el siglo XVIII como hemos visto) o electrónica a nivel global (una visita al sitio YouTube puede comprobar esta aserción). El conjunto de estrofas que comprenden las decenas de versiones documentadas de esta canción, muchas de ellas en el trabajo de campo de Susana WeichShahak que sirve de base a este estudio, es un tema que sobrepasa los límites de este artículo dedicado solamente a ciertos aspectos de la melodía de "Morenica".

Actualmente, una versión musical especifica de esta canción sefardí acapara la gran mayoría de sus apariciones en el campo de la música judeoespañola, muy especialmente en Israel. Este estudio se desenvuelve alrededor de los procesos sociales por los cuales tal versión de "Morenica" adquirió su estatus canónico borrando o ignorando a otras versiones más cabales que circulaban en el pasado y que todavía se pueden escuchar de boca de alguna que otra cantadora sefardí tradicional. Más aún, se agrega al estatus especial de "Morenica" el hecho de que exista abundante documentación sobre su presencia en la lírica española renacentista, de la cual Attias ya estaba muy informado ${ }^{3}$. Esto permite, en el plano literario, examinar esta canción sefardí en un rico contexto hispánico general y afirmar, en base a clara evidencia documental, que se trata de uno de los más claros casos de supervivencia (renacentista y posiblemente medieval) hispánica en el repertorio judeoespañol moderno de tradición oral. "Morenica" en resumen, es un caso excepcional que confirma la afiliación judeoespañola a la antigua lírica hispánica, una idea que nutre la imaginación moderna la cual injustificadamente transpone esta idea a casi la totalidad del repertorio sefardí que es de creación mucho más reciente.

Weich-Shahak ha recogido treinta y dos versiones de esa canción catalogadas en el Archivo Sonoro de la Biblioteca Nacional de Israel en Jerusalén (NSA). A éstas se agregan muchos más testimonios recogidos por otros etnógrafos, y muy especialmente las veintiséis versiones de la sección Ladino de Kol Israel, ahora incorporadas al Archivo Sonoro de la Biblioteca Nacional y facilitadas online en el sitio del Instituto Maale Adumim². Asimismo existen diez versiones recogidas por Manuel Manrique de Lara a principios del siglo XX que forman parte de la colección del Instituto Universitario Seminario Menéndez Pidal (Armistead et al., 1978, vol. III, pp. 340-41).

\footnotetext{
${ }^{3}$ El estudio literario de La llamada a la morena demanda, como se ha recalcado, un estudio separado. El tema de la morena es ya mencionado en Arte de la lengua española castellana (1626) del catedrático de griego y de árabe en la Universidad de Salamanca, Gonzalo Correas y el tema ya esta se encuentra en una cuarteta citada en la comedia de Lope de Vega Servir a señor discreto (1610-2): "Mariquita me llaman/los arrieros,/Mariquita me llaman,/voime con ellos”, citado en Frenk, 1963, p. 260. Para un resumen del tema en la lírica hispánica medieval y renacentista en relación con "Morenica” y copiosa bibliografía vigente hasta 1971, véase Armistead y Silverman, 1971, pp.99-100 y entre los más recientes estudios véase Pérez Díaz, 2015.

${ }^{4}$ Recuperado de http://folkmasa.org/avshir/pshir.htm.
} 
Sin embargo, para el presente argumento, las versiones de la colección Weich-Shahak, muchas de ellas ya publicadas, son más que suficientes ${ }^{5}$. Las melodías de estas versiones presentan una notable uniformidad musical que se trata a continuación. Ellas difieren de las versiones divulgadas en grabaciones comerciales a partir de los años sesenta del siglo pasado. La génesis de esta diferencia musical comprende el núcleo de este estudio ${ }^{6}$.

Comenzaremos con tres versiones de "Morenica" recogidas en Israel entre 1983 y 1986 de cantantes originarios de la ciudad de Esmirna e emigrados a Israel después de 1948. Como el énfasis de este estudio es en la música, los textos pertinentes aparecen en el apéndice a este artículo. Asimismo, se transcriben las melodías usando una misma tónica para facilitar la comparación.

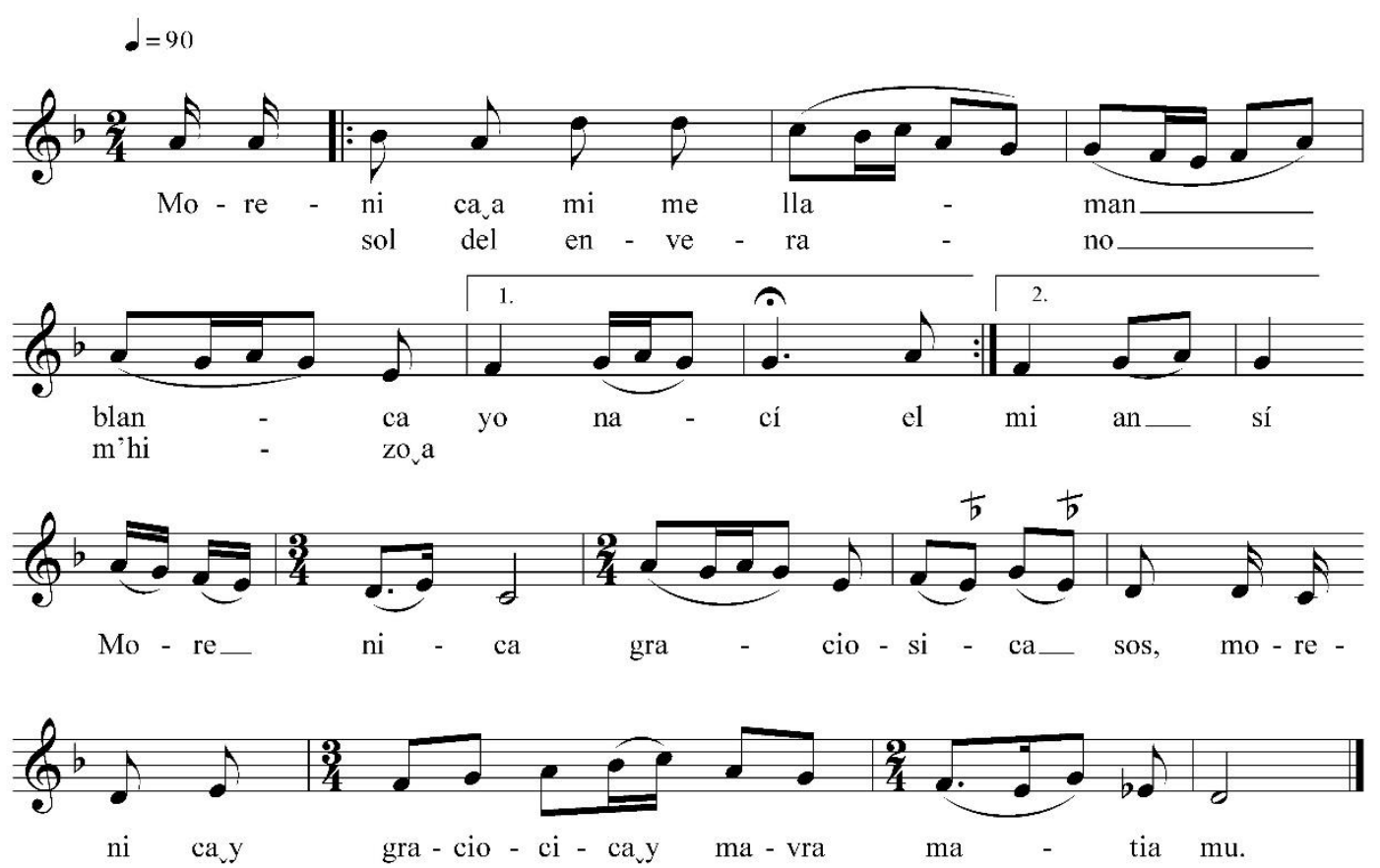

Fig. 1: Versión cantada por Rahel Altalef-Brener, de Esmirna, grabada en Jerusalén, el 27 8.1986, NSA Yc 2774/22.

\footnotetext{
${ }^{5}$ Doce versiones en Weich-Shahak 2012: 234-242 y de ellas, cuatro grabaciones en Weich-Shahak, 2014.

${ }^{6}$ La versión cantada por Gloria Levy (Levy, 1958), el primer disco de temas sefardíes publicado en América en el periodo de post-guerra, es afín a las grabaciones de campo de Weich-Shahak, lo que proporciona un terminus ante quem para la persistencia de este modelo melódico también en fuentes comerciales.
} 


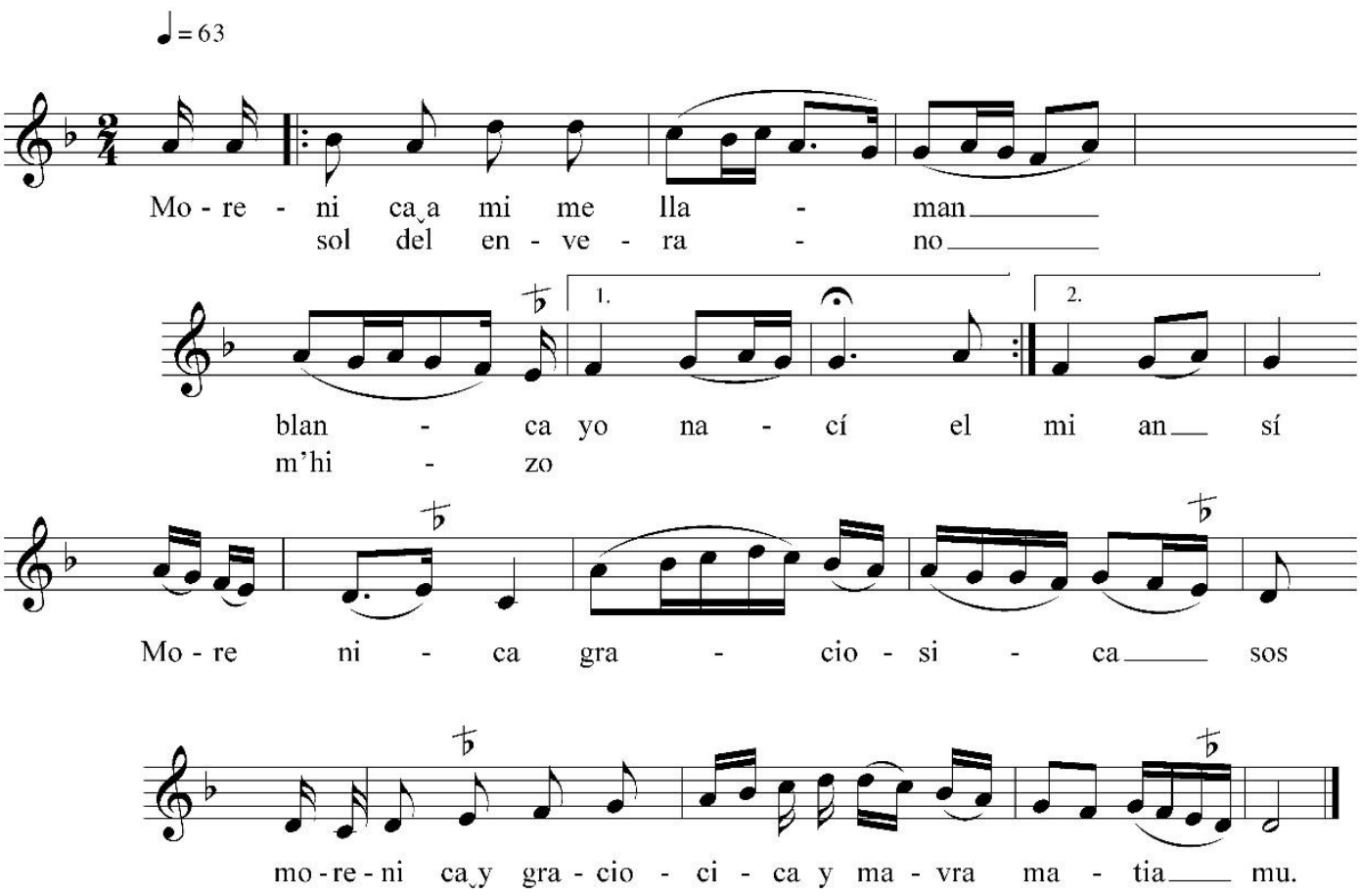

Fig. 2: Versión cantada por Josepo Burgana, nacido en Esmirna, grabado en su casa en Lod, 19.3.1984, NSA Y 5433/3.
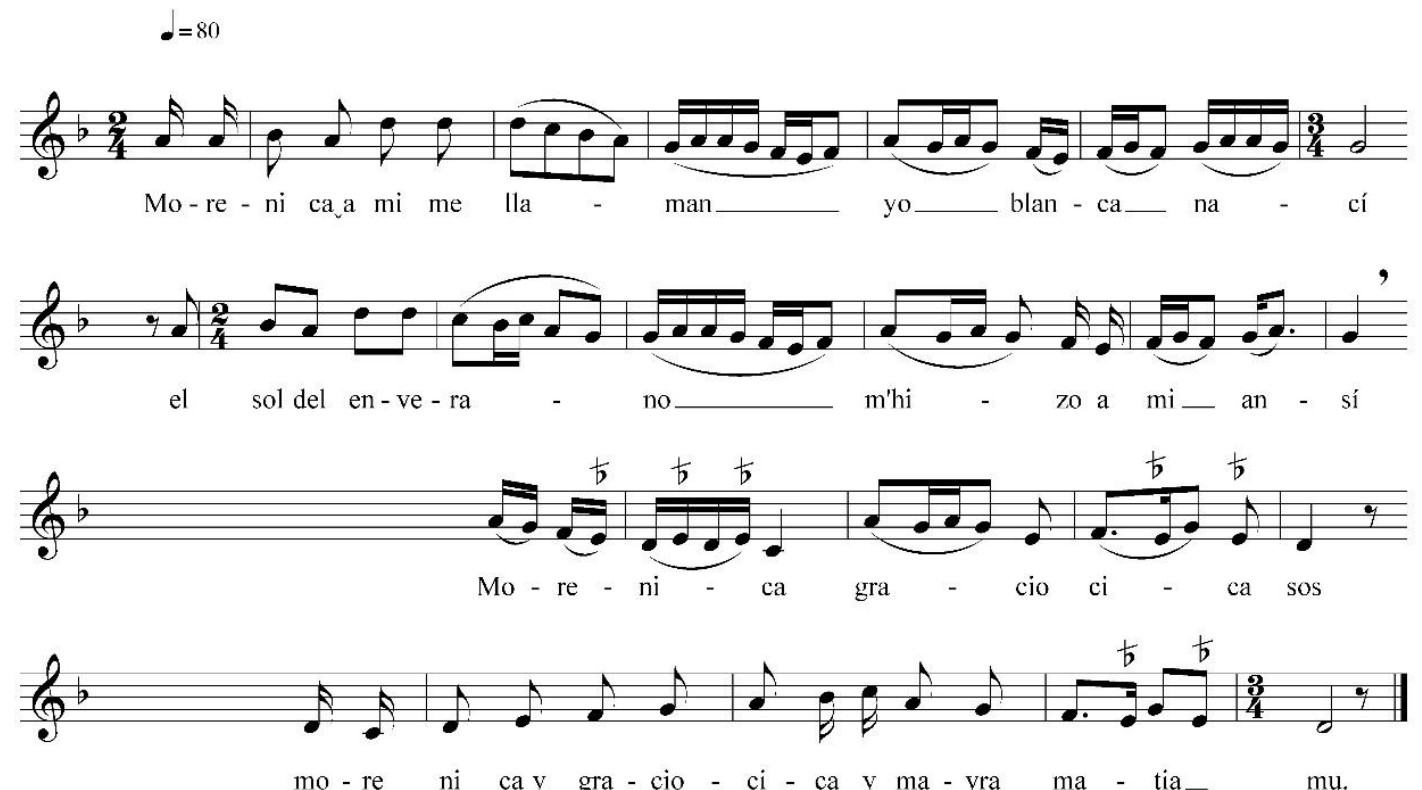

Fig. 3: Versión cantada por Malka Dayan-Mayesh y su hermana Rahel Mayesh, nacidas en Esmirna acompañándose con percusión de cucharas, grabadas en Yahud, 30.5.1983, NSA Y 3979/1, (encuesta en colaboración con Pamela Dorn). 
Seleccionamos estas tres versiones de Esmirna, porque reflejan la patente uniformidad de la tradición oral de esta comunidad sefardí, en cuyo repertorio judeoespañol "Morenica" cuenta con una presencia destacada ${ }^{7}$. Musicalmente la versión esmirnaica consiste de dos frases repetidas, la primera (A) contiene la estrofa y la segunda (B) es un estribillo que se repite, texto y música, después de cada estrofa. Distinguen a estas dos frases su diferente registro. Frase A se mueve descendiendo en el pentacordio alto de la melodía (de re a sol, tocando el fa, subtónica del sol) y la frase B descendiendo en el tetracordio bajo (de sol a re, con pausa en la subtónica do).

Versiones de repertorios de otras comunidades reflejan la relación que esta cantiga o cantica sefardí tiene con las bodas, la cual ya se refleja claramente en la versión de David Hacohen la cual incluye cuatro claros episodios seriados: la llamada a la morena (dos estrofas), la bajada de la morena a la nave (metáfora del marido que se la llevará; dos estrofas), los vestidos de la novia (tres estrofas), y la bajada de la novia a la ceremonia del casorio (quidušin, dos estrofas). A la función nupcial aluden otras estrofas adicionales parecidas o derivadas de la versión dieciochesca que han sido documentas en una gran variedad de combinaciones y de orden de aparición junto con las de "Morenica". Los tres ejemplos siguientes (Fig. 4, 5 y 6) incluyen las estrofas de "Morenica" entre numerosas otras (y no siempre como primera estrofa de la canción) referentes a la boda. Estos temas literarios son conocidos bajo los títulos de La nave por partir, El vestido de la morena, Las flechas del amor, La escalera de las bendiciones, etc.

En el siguiente cantar de boda (Fig. 4), el texto comienza hablando de una escalera hecha de oro y cristal por la cual el novio vendrá (o subirá) a dar la bendición nupcial (ver transcripción en el Anexo). La melodía es esencialmente idéntica a la de las versiones de "Morenica" de Esmirna, lo que confirma la estrecha relación entre la tradición sefardí de la ciudad de la costa Anatolia con la de la cercana Isla de Rodas.

\footnotetext{
${ }^{7}$ La canción esta copiosamente documentada en Salónica, pero también en otras localidades del ex-Imperio Otomano, como ser Sarajevo, Bulgaria, la Isla de Rodas, Estambul y Jerusalén. Como ya se ha señalado, las versiones textuales difieren sustancialmente de una localidad a otra. Es de destacar una diferencia notoria entre versiones que abren con "Morena" de las que comienzan con su diminutivo, "Morenica". Este diminutivo resuena con la "Mariquita" mencionada por Lope de Vega (véase arriba nota 3) y es una característica peculiar de la tradición judeoespañola, como ya lo demuestra la versión dieciochesca de David Hacohen. Más aun, las versiones que comienzan con "Morenica" contienen generalmente un estribillo de probable creación moderna: "Morenica y graciosica sos, morenica y graciosica y ojos vedrolís" o "Morenica, morenica y sabrosica, mi cara de flor", y en versiones generalmente salonicenses con un texto parcialmente en griego: "Morenica y graciosica sos, morenica y graciosica mavra matia mou" o "Morenica y graciosica sos, tu morena y yo gracioso, mavra matia

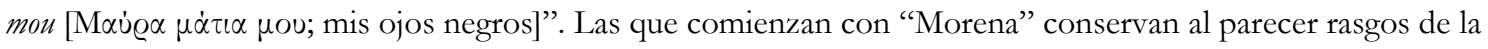
lírica hispánica antigua y casi todas carecen de estribillo.
} 


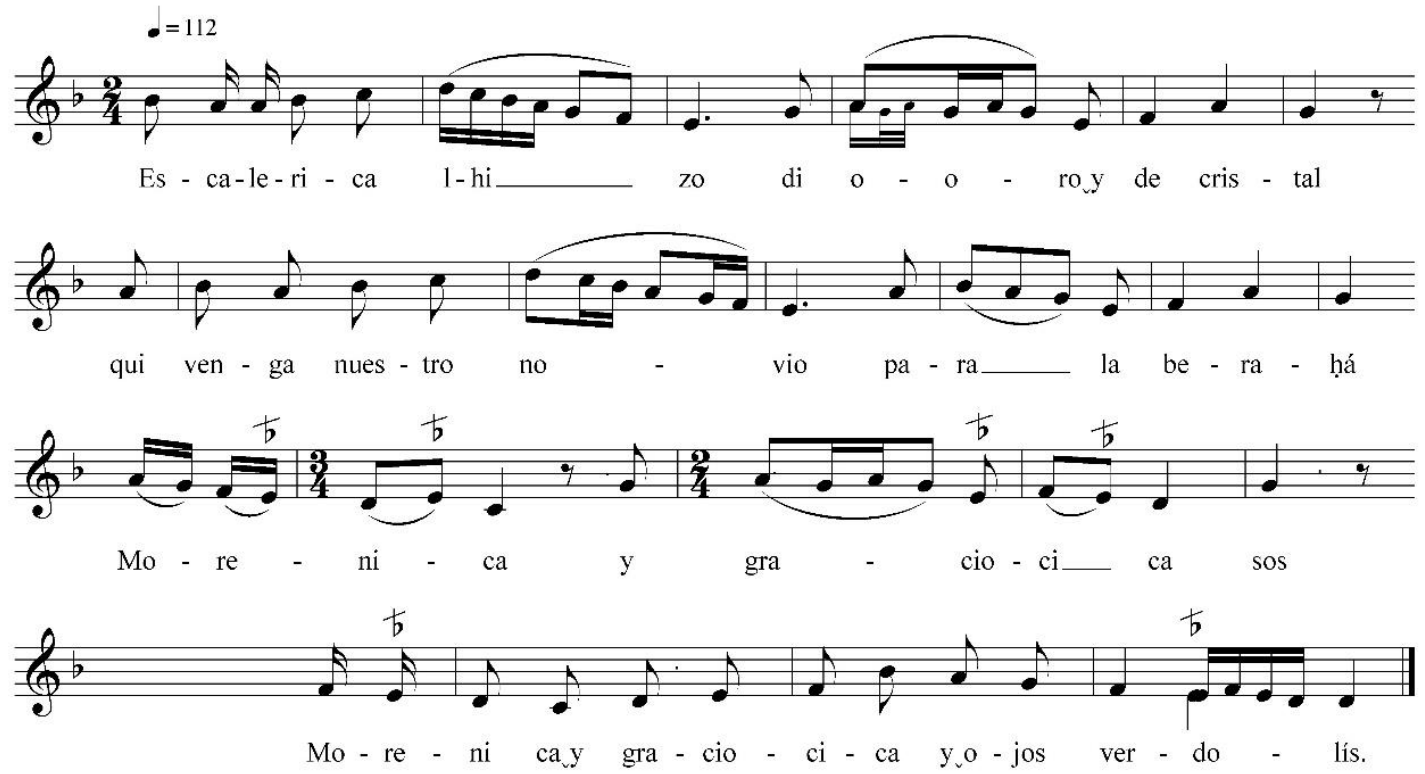

Fig. 4: Versión cantada por Rosa Avzaradel-Alhadef, nacida en Rodas, grabada en su casa en Ashdod el 24.12.1988. NSA Y 5737a/9.

La siguiente versión (Fig. 5), también cantada en la boda, alude al vestido de la novia (al te-li: de hilos rojos, del turco; al = carmesí, tel $=$ hilo, cordón) y específicamente a la ceremonia de su casamiento (quidusin). Solo en las siguientes estrofas, aparece el texto de "Morenica". Esta versión difiere musicalmente de las versiones anteriores de la zona de Esmirna-Rodas. La diferencia registral entre las dos frases es menos dramática, la melodía es mucho menos melismatica, las dos frases descienden a la tónica, cada verso se repite y no hay estribillo.

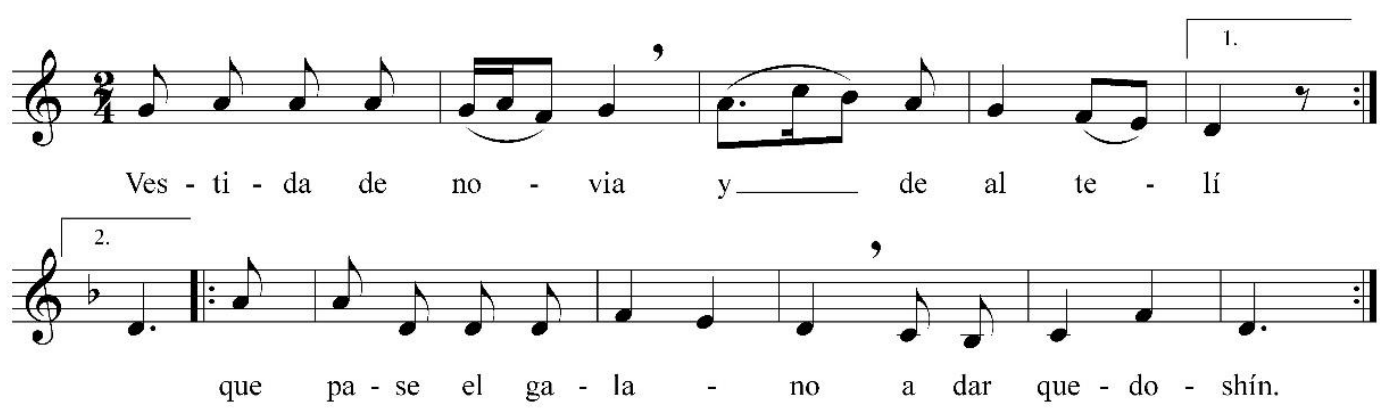

Fig. 5: Versión cantada por Mazaltó Lazar, nacida en Mustafapaşa, creció en Sofia (Bulgaria), grabada en Jerusalén, 14.7.1975, NSA Yc 1038/10. 
En otras versiones, como en la siguiente (Fig. 6), la escalera es de oro y de marfil. Nótese que esta versión es musicalmente idéntica a la anterior (no. 5), lo que sugiere una afinidad musical entre tradiciones sefardíes relativamente "periféricas" del centro otomano (Sofia, Jerusalén) relacionadas con este antiguo canto de boda que difieren de las versiones del eje Esmirna-Rodas-Salónica.

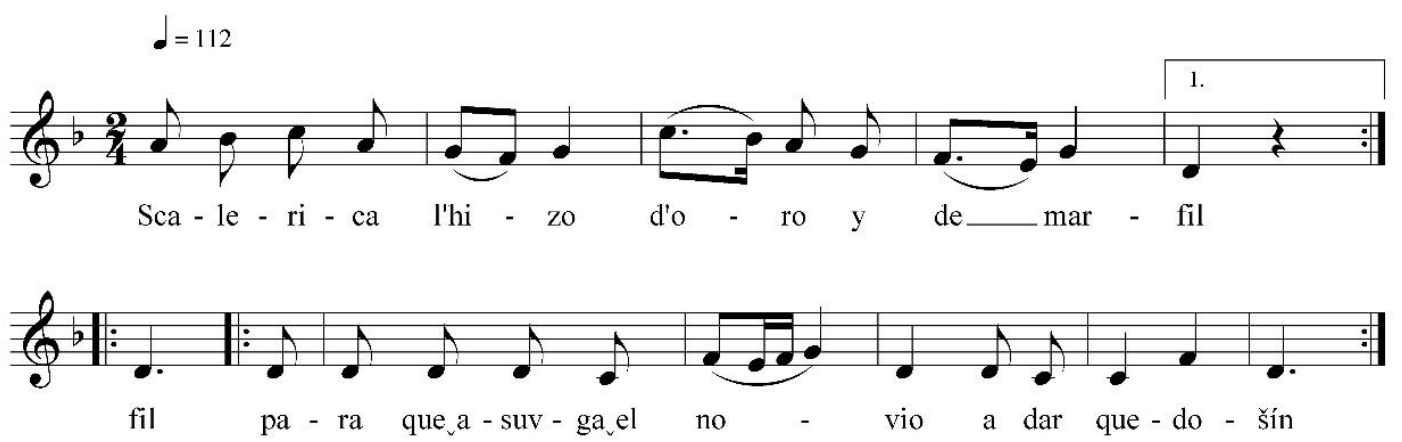

Fig. 6: Versión cantada por Rivka Peretz-Chiniyo, nacida en Jerusalén, grabada en Jerusalén, el 12.7.1983, NSA Yc 2114/22.

Habiendo establecido las pautas poéticas y musicales generales de "Morenica" y sus afines en las tradiciones sefardíes pasaremos al tema principal de este estudio, o sea su recepción contemporánea fuera de la comunidad sefardí y su destino comercial en Israel y fuera de ella. En numerosas ocasiones, las colaboradoras comentaron a Weich-Shahak que habían oído en la radio cantar "Morenica," de 'otra manera' que en su opinión no era la correcta. Es más: expresaban su opinión con enfado y desdén por la versión popularizada en Israel, interpretada por destacados cantantes populares en arreglos muy diferentes.

La versión que generó esta 'otra manera' de cantar "Morenica” y que desencadenó la explosión de grabaciones comerciales que plasmó tal versión en Israel es en forma paradójica su traducción del judeoespañol al hebreo de Moshe Giora Elimelekh titulada "Sheharhoret". Esta versión en hebreo fue lanzada al público en el álbum pionero del duo Parvarim de 1967, Haparvarim beshirat Ladino (Judeo-espagnol songs, CBS Records, 62947). Este álbum combina canciones litúrgicas sefardíes en hebreo con canciones en judeoespañol en la lengua original y en traducción al hebreo, y se destaca por su suave y agradable sonido de música de cámara generado por dos cantantes de voz acogedora acompañándose a sí mismos con guitarras acústicas". La inclusión de "Sheharhoret" en la exitosa obra teatral musical Bustan sefaradí de Itzhak Navon que tuvo su premier en 1969, extendió su presencia en la escena israelí.

\footnotetext{
${ }^{8}$ Sobre la transformación de canciones en judeoespañol a canciones israelíes en hebreo véase Seroussi, 2002.

9 Esta estética es diametralmente opuesta a los arreglos orquestales del long-play Romansot be-ladino ("Romances en Ladino", en hebreo españolizado), Romantic Ballads from the Great Judeo-Espagnol Heritage ("Baladas románticas del gran patrimonio judeo-español”, en inglés afrancesado) del distinguido cantante
} 


\section{EDWIN SEROUSSI BARGMAN Y SUSANA WEICH SHAHAK}

Pero fue el cover de esta versión en hebreo cantada por Esther Ofarim e incluida en su álbum de 1972, Ofarim Only in Hebrew (Phonodor 13034A) el que transformó a "Sheharhoret" en un clásico del repertorio israelí, independientemente (y a veces sin tener noción) de su origen judeoespañol. Esta versión ha sido consecuentemente replicada por muchísimas otras cantantes y grupos alrededor del globo hasta el presente. Entre estas se destaca la influyente versión de Shlomo Bar y su conjunto Habrera Hativ'it, un ensamble pionero de la música denominada 'étnica' en Israel, la versión local de la "World Music” (Seroussi 2012).

Las diferencias melódicas y rítmicas entre la rica evidencia etnográfica de "Morenica" recogida por Weich-Shahak a lo largo de cuatro décadas de trabajo de campo y la versión comercial popularizada por el duo Parvarim y sus consecuentes versiones ejemplifica procesos de canonización de canciones judeoespañolas en la era de la reproducción mecánica. La mayoría de las producciones comerciales de canciones judeoespañolas grabadas en Israel en las décadas de los años 1960 y 1970 se basan en notaciones musicales publicadas por el cantante, compositor y folklorista israelí de origen turco, Isaac Levy (1959-1973). Ya en 1995 Seroussi (1995) notaba en detalle el influjo que los cuatro volúmenes de canciones judeoespañolas transcritas y publicadas por Levy habían tenido en la recepción y eventual popularización de este repertorio mucho más allá de los confines de la comunidad sefardí que mantuvo este acervo poético y musical como parte integral de su vida comunitaria.

Levy incluyó dos versiones de "Morenica" en el primer volumen de sus Chants judeoespagnols (nos. 21 y 24), el volumen que ha tenido el máximo impacto en la comercialización de la canción judeoespañola. Infortunadamente Levy no aportó ninguna información de tipo etnográfico sobre el origen geográfico de las canciones que publicó y tampoco de quien las documentó. Por lo tanto quedan inciertas las razones detrás de las diferencias entre las dos versiones. La versión no. 21 es la que canta el dúo Parvarim y la cual obtuvo una persistente presencia en los medios de comunicación radiofónicos de Israel, a las cuales accedían, entre tantas, las cantadoras sefardíes entrevistadas por Weich Shahak. Analicemos a continuación esta versión de Levy (Fig. 7).

popular Yehoram Gaon, publicado un año después del álbum de los Parvarim. El álbum de Gaon determinó el canon comercial básico de la canción judeoespañola pero no incluye a "Morenica" (Seroussi, 2000). 


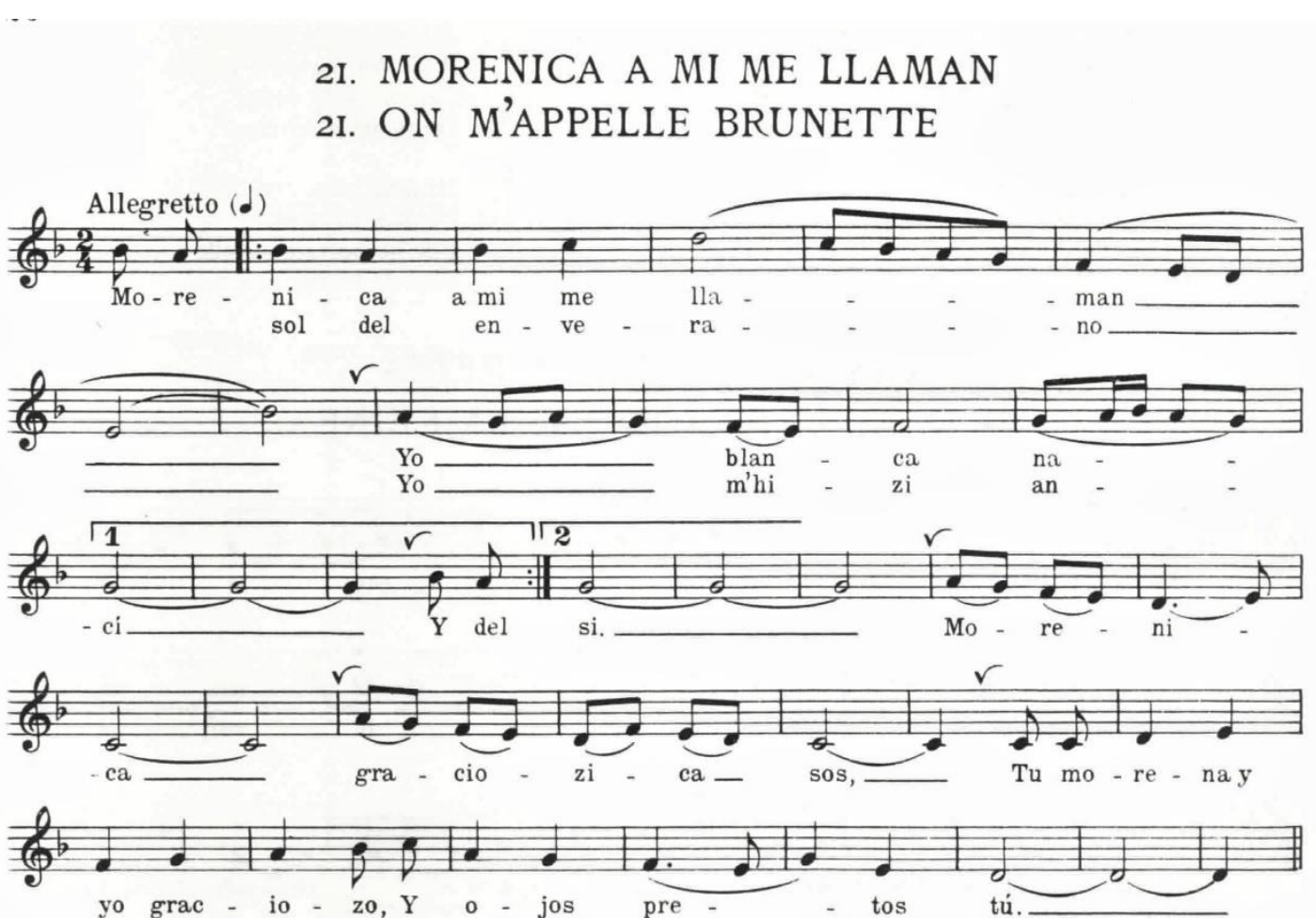

Fig. 7: Facsímile de I. Levy (1959). Chants judeoespagnols, 1(21).

Las diferencias entre esta versión y todas las documentadas por Weich Shahak y, como veremos más adelante, en la discografía histórica desde principios del siglo XX, se encuentran a varios niveles. El más evidente es el nivel rítmico. En los primeros tres compases los valores rítmicos en la versión de Levy son proporcionalmente dobles en comparación con las versiones de tradición oral, incluida la versión no. 24 de Levy mismo. Este trastorno rítmico crea también un énfasis sobre la tónica en la octava alta en el tercer compás (re en la segunda octava) que en las versiones orales tiene un valor rítmico efímero. Pero también a nivel melódico encontramos diferencias, por ejemplo en la prolongación del salto de quinta disminuida en los compases 6-7. Más aun, la frase B tiene una estructura simétrica de unidades de cuatro compases que no está presente en las versiones recogidas por WeichShahak. Esta simetría, agrega a la popularidad de la versión no. 21 de Levy. Además, la eliminación de melismas y la claridad modal que tal "limpieza" crea, provee una línea melódica más dócil a la armonización. En la comparación paradigmática (Fig. 8) de la versión de Levy con las tres versiones tradicionales de "Morenica" (véase arriba ejemplos de las Fig. 3, 1, 2, transpuestas a la misma tonalidad $r e$ ) se pueden observar los cambios de valores rítmicos y la des-melismatizacion de la línea melódica. 


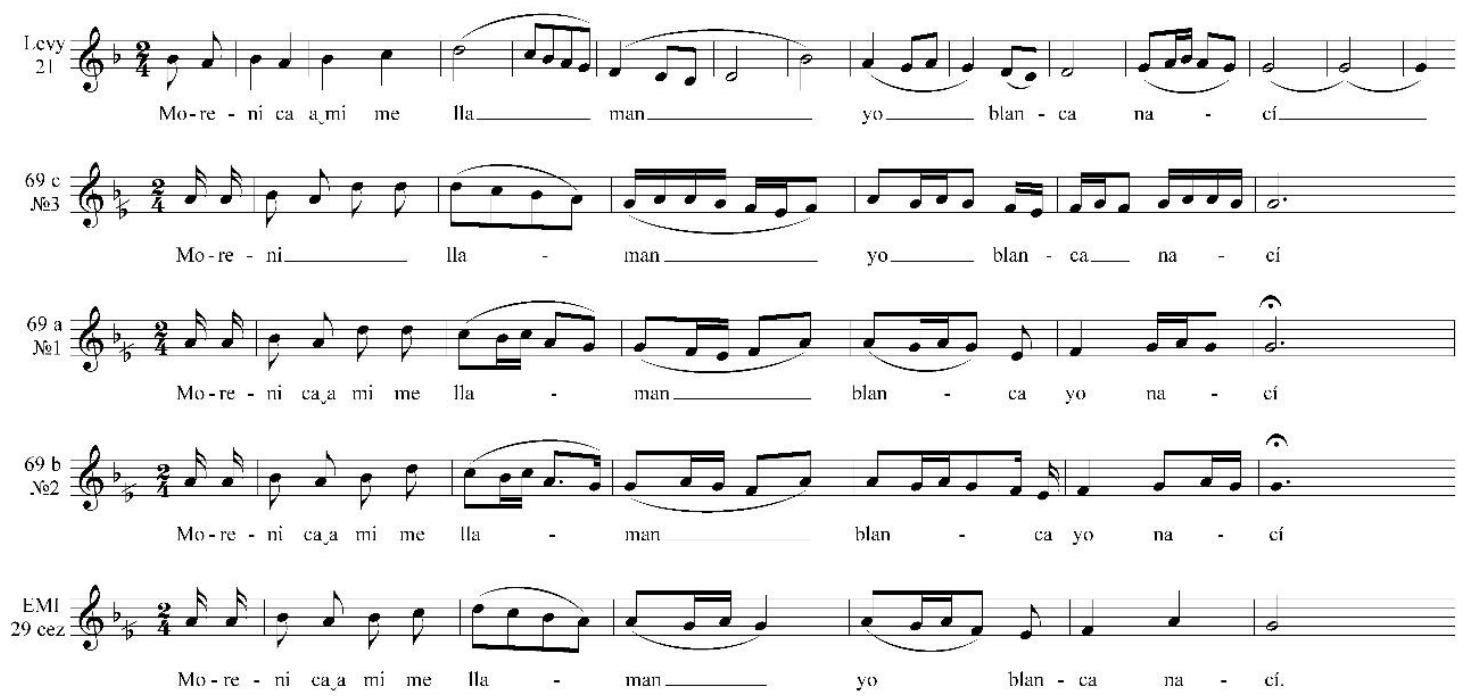

Fig. 8: Comparación paradigmática tabulada de la primera frase de la versión de Levy (vol. 1 [1959], no. 21) con versiones orales (ver arriba Fig. 3, 1 y 2 respectivamente).

Es legítimo aquí preguntar lo siguiente en referencia a la versión no. 21 de Isaac Levy: ¿Se trata de una versión que solo Levy documentó y que se perdió de la memoria popular o de una distorsión generada por un error de transcripción musical o en el proceso de copiar la partitura en el cual los valores rítmicos son trocados (corches por negras, negras por blancas, etc.)? Este tipo de distorsión rítmica en un fenómeno común en los dictados musicales de estudiantes de solfeo. ¿Sería entonces un error de transcripción de Levy, o de los agentes que lo asistieron en las transcripciones de estas melodías? ¿O podría ser que Levy "arregló" la melodía melismática y asimétrica de la mayoría (pero no de todas) las versiones orales para facilitar su futuro destino como canción popular? Nunca sabremos las respuestas a estas preguntas. Lo que sí sabemos es que eventualmente, a los pocos años de ser publicada por Levy, esta melodía de "Morenica" con el texto traducido al hebreo se transformó en un shlager internacional.

Pero no la transcripción de Levy al pie de la letra es la que dominó la toda la comercialización de "Morenica" sino que en el sendero que lleva de la notación musical a la primera grabación se creó otra alteración rítmica que agrego todavía más espacio o "aire" a los cantantes. El segundo compás de la no. 21 de Levy aparece en la versión de los Parvarim duplicada una vez más (o sea cuadriplicada en comparación con las versiones orales como las que recogió Weich-Shahak). Las largas notas generosamente distribuidas por Levy ofrecieron a los cantores y a las cantoras la ocasión de lucir sus capacidades líricas y expresivas. También en este caso no sabemos qué agente es el responsable de esta duplicación rítmica. Agregamos aquí que no todas las versiones comerciales emplean esta doble duplicación, algunas siguiendo a los Parvarim si lo hacen y otras siguen la transcripción de Levy fielmente. La Fig. 9 muestra esta extensión rítmica. 


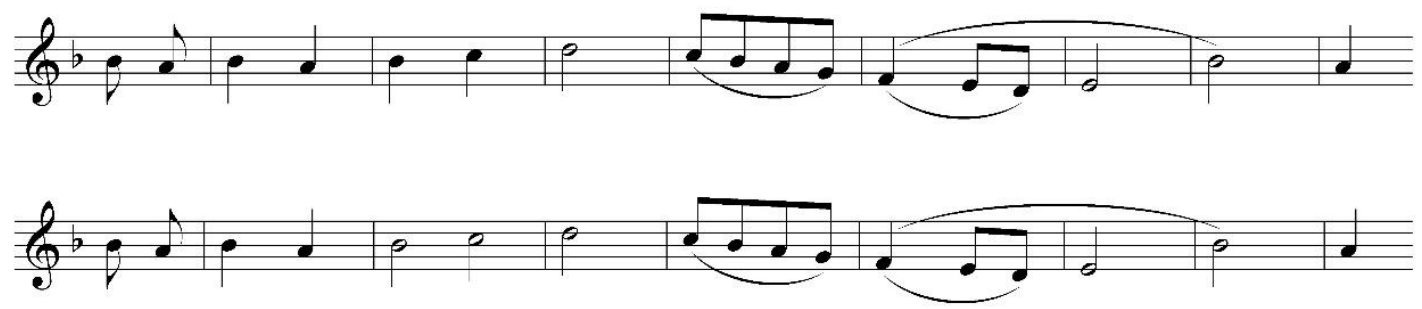

Fig. 9: Comparación entre la versión de la primera frase de Levy [1959, 1(21)] con la de Parvarim.

Retornamos hacia el final de este estudio sobre "Morenica" a las versiones documentadas y grabadas comercialmente a principio del siglo XX. Este material da una pauta de la continuidad en la transmisión de canciones populares sefardíes como así también permiten localizar las modificaciones no intencionales o premeditadas generadas por diversos agentes (interpretes, coleccionistas, arregladores, etc.) que han actuado sobre esta canción. Por ejemplo, la reciente publicación de grabaciones antiguas de canciones populares judeoespañolas del EMI Archive Trust ofrece la oportunidad de escuchar "en vivo" una versión de "Morenica" tal y como se la podía escuchar en una boda en Salónica o en un café cantante en Estambul alrededor de 1900 (Havassy y Seroussi 2020). Nuestra canción está interpretada por la Compagnie Espagnole de Salonique (CES), un grupo que se formó en Salónica y efectuó sus grabaciones en Estambul en 1907 (Zonophone 104114). ${ }^{10}$ La comparación paradigmática entre esta versión y la versión no. 21 de Isaac Levy (Fig. 10) muestra que tal cual como hemos visto en la comparación con las grabaciones de campo, la versión del CES es rítmicamente muchísimo más concisa que la de Levy.

\footnotetext{
10 Otro gran cantador sefardí otomano, Haim Effendi, grabó "Morenica" en la primera década del siglo XX pero no poseemos una copia de su grabación. Sin embargo, existe una transcripción musical de su versión preparada en 1911 por Manuel Manrique de Lara y enviada a Don Ramón Menéndez Pidal en Madrid (Catalogo Menéndez Pidal, Encuesta 113, CMP AA45.9). También el cantante sefardí Albert Beressi la grabó alrededor de 1908 (Odeon 54473). El 31 de marzo de 1931, en un estudio en Viena, graba "Morenica" para la firma Gramophone (70-1990) el cantante sefardí Dario Medina acompañado en el piano por el distinguido músico judío de Sarajevo Avraham Suzin quien también arregló la canción para voz y piano en un estilo bastante sofisticado. El título en el disco, "D’aquellas ventanas me arrojan flechas (Romanza vieja judía española)", refleja claramente la influencia española moderna. A pesar del título del disco, Medina comienza la canción con la primera estrofa de "Morenica". La difusión de nuestra canción en grabaciones comerciales antes de la Segunda Guerra Mundial son un testimonio de su gran popularidad.
} 


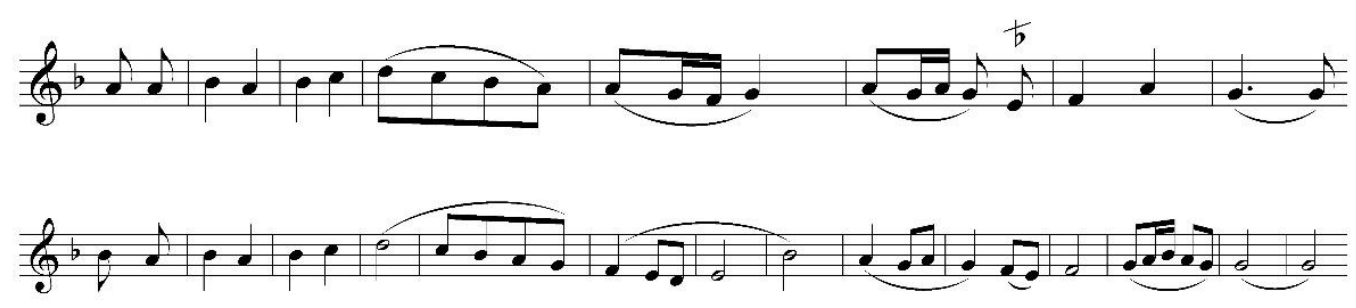

Fig. 10: Comparación entre la primera frase de la versión de la Compagnie Espagnole de Salonique (1907) con la de Levy (vol. 1 [1959], no. 21).

Otra versión de "Morenica" de la primera mitad del siglo XX en notación musical ofrece el distinguido compositor y etnomusicólogo sefardí Alberto Hemsi (1995, no. 115) ${ }^{11}$. En base a su transcripción de campo, Hemsi compuso un elaborado arreglo de nuestra canción, que se incluye en el opus 34 (no. 4) de sus Coplas sefardies para voz y piano. No sorprende que la versión de Hemsi es prácticamente idéntica desde el punto de vista musical a las versiones de Esmirna-Rodas que recogió Susana Weich-Shahak y que se analizaron en detalle más arriba. Toda la evidencia de principio del siglo XX sobre "Morenica" apunta a que la versión no. 21 de Levy fue elaborada en base a una labor de tipo etnográfico, pero fue manipulada de acuerdo a parámetros estéticos en vista a una difusión moderna y armonizada. No se consideran aquí los aspectos éticos de tal acción. Solamente se presenta la clara evidencia de cómo fue concebida la versión de "Morenica"/"Sheharhoret" que tanto ofuscaba a las colaboradoras de Weich-Shahak.

Considerando la consistencia de las copiosas versiones de la melodía de "Morenica" en su vertiente sefardí del Este del Mediterráneo documentadas a partir de 1907, sea en la versión predominante de Esmirna-Rodas-Salónica o en la más simplificada versión del cantar de bodas de comunidades sefardíes que denominamos periféricas, se puede proponer de que se trata de una estructura melódica de remarcable antigüedad. La tenacidad con la cual la vertiente hispánica de "Morenica" se ha conservado entre los sefardíes en su aspecto literal hace pensar que quizás también su faceta musical es arcaica. Seguramente el jazán David Hacohen cantaba una versión muy semejante a las que Weich-Shahak recogió en su labor de campo.

Tal tenacidad en la transmisión oral de "Morenica" en su aspecto literal la ratifica el siguiente ejemplo. En el capítulo LXXXIV del ya mencionado Arte de la lengua española castellana de Gonzalo Correas (véase arriba nota 3), llamado De la medida de los versos castellanos el autor se ocupa de las "seguidillas" (Correas 1954 [1626], p. 438). Analizando su estructura de estrofas de cuatro versos de rima en los versos pares, alternando versos de siete y cinco

\footnotetext{
11 Otra versión temprana del texto de "Morenica" la recogió Leo Wiener (1903, pp. 264-265) de una cantadora residente en Belgrado, pero originaria de "Bosnia" (o sea de Sarajevo). El texto es sorprendentemente idéntico al que documentó David Hacohen otro oriundo de Sarajevo un siglo antes.
} 
sílabas, una estructura que encontramos también en las versiones sefardíes de "Morenica", Correas presenta como ejemplo de seguidilla (ídem, p. 453), un texto cuya quinta estrofa dice:

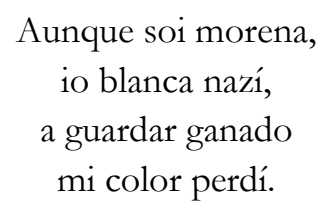

Esta misma estrofa, rarísima en versiones orales, aparece también en el repertorio judeoespañol en una versión cantada por Clara Kadmon-Cohen, oriunda de Sarajevo (grabada en Jerusalén, 14.1.1987, NSA Y5671/24):

\author{
Morena me llaman \\ blanca yo nací \\ bekliando el estado \\ mi color perdí.
}

Bekeliando, es un vocablo de origen turco, derivado del verbo beklemek que significa guardar (con la conjugación verbal del español del gerundio en "ando", propio del judeoespañol al adoptar un término de otra lengua). Otra versión originada en la misma Sarajevo, cantada por Gina Camhy es aún más cercana a la de Correas (Kol Israel FLAD 201/04, grabada en 1984; sobre Camhy véase, Jovanović, 2016) dice:

\author{
Morena me llaman \\ yo blanca nací \\ Di pasiar ganado \\ mi color perdí.
}

Todo esto significa que en una lejana esquina balcánica del ex-Imperio Otomano, Sarajevo, la memoria de la lírica hispánica renacentista todavía estaba viva en la segunda mitad del siglo $\mathrm{XX}^{12}$. Esta vitalidad de la memoria comunitaria sefardí da lugar a nuestra propuesta de que no solo en el texto sino que también en la melodía de "Morenica" en grabaciones de campo hechas en Israel hace ya casi medio siglo o en grabaciones comerciales de principios del siglo XX escuchamos ecos de tal venerable tradición poética-musical judeoespañola e

\footnotetext{
12 El motivo ganadero, reflexión de la sociedad campesina ibérica del siglo XVI, perdió su vigencia entre las cantantes sefardíes después de la expulsión como consecuencia del proceso de urbanización de los sefardíes en el Imperio Otomano. La mayoría de las versiones sefardíes de "Morenica" que conservan la estructura de esta estrofa dicen "de pasear galana".
} 


\section{EDWIN SEROUSSI BARGMAN Y SUSANA WEICH SHAHAK}

hispánica. Pero al mismo tiempo hemos visto como un "accidente" moderno ha alterado a esta melodía conservada desde tiempos inmemoriales y reproducido ad infinitum tal alteración. Los procesos tecnológicos de reproducción sonora, transcripción en notación musical, impresión, distribución, recreación y consumo son los que han plasmado tales cambios que amenazan a hacer olvidar la versión tradicional de "Morenica" que sobrevivió, al menos en su aspecto literario, durante cinco siglos.

\section{BIBLIOGRAFIA}

Armistead S. G. \& J. H. Silverman (1971). Judeo-Spanish Ballads from Bosnia. Philadelphia: University of Pennsylvania Press.

Armistead, S. G. et al. (1978). El romancero judeo-español en el Archivo Menéndez Pidal (Catálogoindice de romances y canciones), 3 vols. Madrid: Cátedra Seminario Menéndez Pidal.

Attias, M. (1972). Cancionero sefardí. Tel Aviv: Centro de estudios sobre el judaísmo de Salónica.

Correas, G. (1954 [1626]). Arte de la lengua española castellana. Ed. Emilio Alarcos García. Madrid: Selecciones Gráficas.

Frenk Alatorre, M. (1963). Lope, Poeta Popular. Anuario de Letras, III, pp. 253-265.

Havassy, R. \& Seroussi, E. (2020). Eastern Mediterranean Judeo-Spanish Songs from the EMI Archive Trust (1907-1912). Jerusalem: Jewish Music Research Centre (Anthology of Music Traditions in Israel, 27, AMTI 2001). Recuperado de https://jewishmusic.huji.ac.il/content/22952

Hemsi, A. (1995). Cancionero sefaradí [edición con introducción de E. Seroussi en colaboración con P. Díaz-Mas, J. M. Pedrosa y E. Romero]. Jerusalem: Jewish Music Research Centre.

Jovanović, Ž. (2016). Gina Camhy: una primera aproximación a la vida y obra de la autora sefardí de Bosnia. En P. Díaz-Mas \& E. Martín Ortega (Eds.). Mujeres sefardíes lectoras y escritoras, siglos XIX-XXI (pp. 223-242). Frankfurt a. M., Madrid: Vervuert Verlagsgesellschaft.

Levy, G. (1958). Sephardic Folksongs sung by Gloria Levy. New York: Folkways Records. 
AVATARES DE LA TRADICIÓN ORAL EN LA ERA DE LA REPRODUCCIÓN MECÁNICA:

LA MORENICA JUDEO-ESPAÑOLA HOY

Levy, I. (1959-1973). Chants judeo-espagnols, 4 vols, vol. I, London: Federación Sefaradí Mundial; Vols. II-IV, Jerusalem: The Author.

Pérez Díaz, E. (2015). El sol y la morena en la antigua lirica hispánica. Revista de Folklore (400), pp. 62-67.

Seroussi, E. (1995). Reconstructing Sephardi Music in the $20^{\text {th }}$ Century; Isaac Levy and his Chants Judeo-espagnols. The World of Music, XXXVII(1), pp. 39-58.

Seroussi, E. (2000). Imagen e imaginación en la música sefardí contemporánea. Insula, DCXLVII, pp. 16-19.

Seroussi, E. (2002). De "Morenica" a "Sheharhoret": Canciones en Ladino en el repertorio israelí. En I. Bartal (Ed.). A Century of Israeli Culture (pp. 244-250). Jerusalem: Magnes Press [en hebreo].

Seroussi, E. (2012). Translating from Nothing and from Everything: Israel's Habrera Hativeet ('Natural Gathering') in Retrospective. Journal of Mediterranean Studies, XXI(2), pp. 277-293.

Seroussi, E. (2019). Ruinas sonoras de la modernidad: La canción popular sefardí en la era posttradicional. Madrid: CSIC.

Seroussi, E. \& Havassy, R. (2009). Incipitario sefardí: El cancionero judeo-español en fuentes hebreas (siglos XV-XIX). Madrid: CSIC.

Taradach, M. \& Ferrer, J. (2004). El comentario de Rashi al Cantar de los Cantares: Edición y traducción del Ms. 50H de la Bibliothéque de l'Alliance Israélite Universelle de Paris. Miscelánea de Estudios Árabes y Hebreos, LIII, pp. 407-439.

Weich-Shahak, S. (2012). El Ciclo de la Vida en el Repertorio Musical de las Comunidades Sefardíes de Oriente. Madrid: Editorial Alpuerto.

Weich-Shahak, S. (2014). Cantares Judeo-españoles del Ciclo de la Vida en el Mediterráneo Oriental. Jerusalem: Jewish Music Research Centre, The Hebrew University of Jerusalem.

Wiener, L. (1903). Songs of the Spanish Jews in the Balkan Peninsula. Modern Philology, I(2), pp. 259-274. 
APÉNDICE: SELECCIÓN DE TEXTOS

David Hacohen (Jerusalén, Biblioteca National de Israel, Ms. 413, FOL. 175B)

Morenica me llama

el hî̀o del rey,

Si otra vez me llama

yo me vo con él.

Morenica me llama

yo blanca nací,

de pasear galana

mi color perdí.

Abajéis morena

si habéis de abajar

que la nave tengo en vela

yo me quero andar.

Abajêis morena

si tenéis que venir,

que la nave tengo en vela

yo me quero ir.

Ella se viste de verde

y de zorzolí,

que ansí dice la pera

con el şuftuli.

Ella se viste de verde

y de amarillo,

que ansí dice la pera

con el binbrío.

Ella se viste de verde

y toda color,

que ansí dice la pera

con el inberboy. 
De la mar abajo

lo vide venir

que aquí vos asperan

a dar quidušin.

De la mar abajo

lo vide abajar

que acompañado viene

a dar berakhá.

EJEMPLO NO. 1. MORENICA A MÍ ME LLAMAN

NSA Yc 2774/22 - Rahel Altalef-Brenner (Izmir)- Jerusalem, 27.8.1986

Morenica a mí me llaman

blanca yo nací:

el sol del enverano

m'hizo a mi ansí.

Morenica, graciosica sos,

Morenica y graciosica y mavra matia mou.

Morenica me llaman

los marineros,

si otra vez me llaman

me vo con ellos.

Morenica...

Decilde a la morena

si quere vinir

la nave ya sta ' $\mathrm{n}$ vela,

que ya va a partir.

Morenica...

Decilde a la morena:

¿por qué no me queres?

con oro y con tiempo 


\section{EDWIN SEROUSSI BARGMAN Y SUSANA WEICH SHAHAK}

a mí me rogarés.

Morenica...

Ya se viste la morena

y de yul yagi

ansina es la pera

con el siftili.

Morenica...

Ya se viste la morena

de amarillo,

ansí es la pera

con el bembrillo.

Morenica...

EJEMPLO NO. 4. ESCALERICA L'HIZO

NSA Y 5737a/9 - Rosa Avzaradel-Alhadef (Rhodos, Greece) - Ashdod, 25.12.1988

Escalerica l'hizo

di oro y de cristal,

que venga nuestro novio,

para la berakhá.

Morenica y graciosica sos,

morenica y graciosica y ojos verdolís.

Morena a mí me llaman

los marineros,

si otra vez me llaman,

me vo con ellos.

Morenica...

Escalerica l'hizo

di oro y de marfil,

que venga el nuestro novio

para los quidusin. 
AVATARES DE LA TRADICIÓN ORAL EN LA ERA DE LA REPRODUCCIÓN MECÁNICA:

LA MORENICA JUDEO-ESPAÑOLA HOY

Morenica...

Morena a mí me llama

el hijo del rey,

si otra vez me llama,

yo me vo con él.

Morenica...

Decild' a la morena

si quere venir,

el barco tengo ' $n$ velas,

que ya va a partir.

Morenica...

EJEMPLO NO. 5. VESTIDA DE NOVIA

NSA Yc1038/10 - Mazaltó Lazar (Mustafapaşa+Sofia) - Jerusalem, 14.7.1975

Vestida de novia

y de al tel-lí,

que pase el galano

a dar quidusin.

- Dicime, galana,

si querés venir.

- Las velas tengo puestas,

no me puedo ir.

D'aquellas ventanas

m'a arronjan flechas

y si son de amores,

vengan derechas 


\title{
EDWIN SEROUSSI BARGMAN Y SUSANA WEICH SHAHAK
}

- Dicime, galana, si querés venir.

- Las velas tengo puestas,

ya me puedo ir.

La palomba blanca

del ojo maví,

llevalde esta carta

al mi chelibí.

Morena me llaman

yo blanca nací,

de pasear, galana,

mi color pedrí.

Morena me llama

el hijo del rey:

si otra vez me llama

yo me vo con él.

VERSION DE LA COMPAGNIE ESPAgNOL dE SALONIQUE, ZONOPHONE 104114.

Transcripcion de Seroussi y Havassy, Eastern Mediterranean Judeo-Spanish Songs from the EMI Archive Trust, (29).

Morena a mí me aman,

yo blanca nací.

Del sol del enverano

yo me hizo ansí.

\author{
Morenica, \\ morenica y sabrosica, \\ mi cara de flor.
}


AVATARES DE LA TRADICIÓN ORAL EN LA ERA DE LA REPRODUCCIÓN MECÁNICA:

LA MORENICA JUDEO-ESPAÑOLA HOY

Morena a mí me aman

los del Bašisten.

Si otra vez me aman

yo me vo con él.

Morenica...

Dicilde a la morena

que yo va partir.

Las naves están en velas,

que yo me vo a ir.

Morenica...

Morena a mí me ama

el hijo del rey.

Si otra vez me llama

yo me vo con él.

Morenica...

Dicilde a la morena

que yo va partir.

Las naves están en velas,

que yo me vo ir.

Morenica...

Fecha de recepción: 22/10/2021

Fecha de aceptación: 14/12/2021 